\title{
Do educated women in Sierra Leone support discontinuation of female genital mutilation/ cutting? Evidence from the 2013 Demographic and Health Survey
}

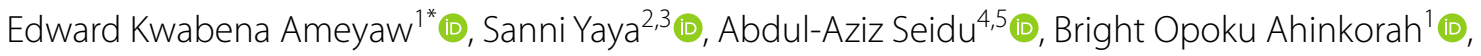
Linus Baatiema ${ }^{4}$ and Carolyne Njue ${ }^{1}$ (D)

\begin{abstract}
Introduction: Female genital mutilation/cutting (FGM/C) comprises all procedures that involve the total or partial elimination of the external genitalia or any injury to the female genital organ for non-medical purposes. More than 200 million females have undergone the procedure globally, with a prevalence of $89.6 \%$ in Sierra Leone. Education is acknowledged as a fundamental strategy to end FGM/C. This study aims to assess women's educational attainment and how this impacts their views on whether FGM/C should be discontinued in Sierra Leone.
\end{abstract}

Methods: We used data from the 2013 Sierra Leone Demographic and Health Survey. A total of 15,228 women were included in the study. We carried out a descriptive analysis, followed by Binary Logistic Regression analyses. We presented the results of the Binary Logistic Regression as Crude Odds Ratios (COR) and Adjusted Odds Ratios (AOR) with 95\% confidence intervals (Cls).

Results: Most of the women with formal education (65.5\%) and $15.6 \%$ of those without formal education indicated that FGM/C should be discontinued. Similarly, 35\% of those aged 15-19 indicated that FGM/C should be discontinued. Women with a higher education level had a higher likelihood of reporting that FGM/C should be discontinued [AOR 4.02; Cl 3.00-5.41]. Christian women [AOR 1.72; $\mathrm{Cl} 1.44-2.04]$, those who reported that $\mathrm{FGM} / \mathrm{C}$ is not required by religion [AOR 8.68; Cl 7.29-10.34], wealthier women [AOR 1.37; Cl 1.03-1.83] and those residing in the western part of Sierra Leone [AOR 1.61; Cl 1.16-2.23] were more likely to state that FGM/C should be discontinued. In contrast, women in union [AOR 0.75; Cl 0.62-0.91], circumcised women [AOR 0.41; Cl 0.33-0.52], residents of the northern region [AOR 0.63; $\mathrm{Cl} 0.46-0.85$ ] and women aged 45-49 [AOR 0.66; Cl 0.48-0.89] were less likely to report that FGM/C should be discontinued in Sierra Leone.

Conclusion: This study supports the argument that education is crucial to end FGM/C. Age, religion and religious support for FGM/C, marital status, wealth status, region, place of residence, mothers' experience of $F G M / C$ and having a daughter at home are key influences on the discontinuation of FGM/C in Sierra Leone. The study demonstrates the need to pay critical attention to uneducated women, older women and women who have been circumcised to help Sierra Leone end FGM/C and increase its prospects of achieving Sustainable Development Goals (SDG) three and five.

Keywords: Discontinue, Female genital mutilation/cutting, Reproductive health, Sierra Leone, Women

*Correspondence: edmeyaw19@gmail.com

${ }^{1}$ School of Public Health, Faculty of Health, University of Technology Sydney, Sydney, NSW, Australia

Full list of author information is available at the end of the article permits use, sharing, adaptation, distribution and reproduction in any medium or format, as long as you give appropriate credit to the original author(s) and the source, provide a link to the Creative Commons licence, and indicate if changes were made. The images or other third party material in this article are included in the article's Creative Commons licence, unless indicated otherwise in a credit line to the material. If material is not included in the article's Creative Commons licence and your intended use is not permitted by statutory regulation or exceeds the permitted use, you will need to obtain permission directly from the copyright holder. To view a copy of this licence, visit http://creativecommons.org/licenses/by/4.0/. The Creative Commons Public Domain Dedication waiver (http://creativeco mmons.org/publicdomain/zero/1.0/) applies to the data made available in this article, unless otherwise stated in a credit line to the data. 


\section{Plain English summary}

Sierra Leone has one of the highest rates of FGM/C in the world. It is the only country in south western Africa with a very high FGM/C rate. The most recent Demographic and Health Survey (DHS) reported a national prevalence of $89.6 \%$. In this study, we investigated women's educational attainment and their beliefs on whether FGM/C should be discontinued in Sierra Leone. We conducted descriptive analysis followed by binary logistic regression analyses. Our results were presented as crude odds ratios (COR) and adjusted odds ratios (AOR) with 95\% confidence intervals (CIs), signifying the level of precision. We noted that women who had a higher education level were more likely to report that FGM/C should be discontinued [AOR 4.02; CI 3.00-5.41]. Christian women [AOR 1.72; CI 1.44-2.04], women who said that FGM/C is not required by religion [AOR 8.68; CI 7.29-10.34] and wealthier women [AOR 1.37; CI 1.03-1.83] were more likely to indicate that $\mathrm{FGM} / \mathrm{C}$ should be discontinued. In contrast, women in union [AOR 0.75; CI 0.62-0.91] and circumcised women [AOR 0.41; CI 0.33-0.52] were less likely to support the discontinuation of FGM/C in Sierra Leone. Our study supports the argument that education is crucial for ending FGM/C. The study illustrates the need to pay particular attention to uneducated women, older women and women who have been circumcised to help Sierra Leone end FGM/C and increase its prospects of achieving SDG three and five.

\section{Introduction}

Female genital mutilation (FGM), also referred to as female genital cutting or circumcision (FGC), comprises "all procedures that involve partial or total removal of the external female genitalia, or another injury to the female genital organs for non-medical reasons" [1]. There are four main types of FGM/C. Type 1 constitutes either a total or partial removal of clitoral glans and/or clitoral hood, while type 2 involves the total or partial removal of the clitoral glans and inner folds of the vulva. The third type-also called infibulation-is characterised by the narrowing of the vaginal opening, while type 4 constitutes any other harmful procedures to females' genitalia for non-medical reasons [1]. More than 200 million females globally have undergone the procedure [1]. People at risk include young girls between infancy and adolescence and in some instances, adult women. Globally, more than three million girls are estimated to be at risk annually [1]. FGM/C has been documented in about 30 countries in Africa, the Middle East and Asia [1, 2]. Currently, FGM/C abandonment interventions trail behind the incidence rate and its prevalence is anticipated to escalate within the next decade if efforts are not expedited [3].
Traditional circumcisers usually execute FGM/C; however, due to adverse health concerns, healthcare providers are involved at times in countries like Egypt, Kenya, Indonesia and Malaysia [2, 4]. The WHO has therefore adopted strategies to deter health workers from the practice [5]. FGM/C subjects women to cruelty, torture and inhuman treatment, and can lead to the contraction of infections including HIV and AIDS [6-8] and even death [1]. It is associated with various short- and long-term health implications, depending on the type. Some of the short-term consequences are haemorrhage, repetitive infections of the low urinary tract and acute anaemia [911]. The long-term consequences include pregnancy and childbirth complications and infertility $[1,12,13]$. Multiple psychological implications have also been reported, including low self-esteem, psychiatric diagnoses, anxiety, somatisation and phobia $[14,15]$.

In many communities, FGM/C is performed on very young females under the age of 18 with devastating results. A report from Sierra Leone in 2018, for instance, revealed that a 10-year-old girl died after undergoing FGM/C as part of a mass initiation of 68 girls into a secret society [16]. The ages of the girls who participated in this initiation ranged from nine to 12 [16].

These and several other appalling implications of FGM/C have led to a strong global call to eliminate FGM/C. A considerable number of UN human rights treaty monitoring bodies such as the Committee on the Elimination of All Forms of Discrimination against Women, the Committee on the Rights of the Child and the Human Rights Committee have condemned the practices and provided recommendations to help states end FGM/C [17]. Target 5.3 of the SDG emphasises the elimination of all harmful practices, such as child, early and forced marriage and FGM/C by 2030 [18].

The World Health Organisation (WHO), the United Nations Population Fund (UNFPA), other local and international human rights organisations and several countries have also introduced measures to end FGM/C. These include the Joint Programme on Female Genital Mutilation, implemented in 15 African countries [19]. The World Health Assembly (WHA) has also passed Resolution WHA61.16 resolution [20], which adopts a multi-sectoral approach to deal with FGM/C. Prevention and protection measures have also been taken globally to stop healthcare providers from performing FGM/C $[5,21]$. For instance, there is the development of healthcare providers' tools and training to manage FGM/C-related complications and prevent new FGM/C cases [21].

$\mathrm{FGM} / \mathrm{C}$ is one of the activities conducted during a rite of passage ceremony to transition girls to adulthood in Sierra Leone [22]. An influential women's group known 
as the Bondo society conducts the ceremony. The Bondo society is a secretive custom or tradition of some women in Sierra Leone, which is rooted in mythology and has FGM/C as its mainstay [23, 24]. Some women believe even talking about the society puts them at the risk of demons or curses [24]. During the ceremony, a traditional leader, locally called a Sowei, performs the act [23, 25].

Sierra Leone is a country with one of the highest FGM/C prevalence globally [26]. It is the only country in south western Africa with very high FGM/C rates [27]. To date, there is no explicit law that prohibits FGM/C in Sierra Leone [28]. There is no strong political will to combat against FGM/C in Sierra Leone, as the traditional FGM/C practitioners, locally known as Soweis, influence females' votes and serve as the link between some communities and the central government $[23,29]$. The practice is considered a social norm. Females who refuse it are sometimes ostracised and labelled as ill-mannered or unready for marriage and forfeit the public recognition earned by those who comply [30].

The most recent Demographic and Health Survey (DHS) of Sierra Leone reported a national prevalence of $89.6 \%$ [31]. Studies have been conducted on various dimensions of FGM/C in Sierra Leone and other subSaharan African countries to understand the possible drivers of the act [23, 32, 33]. Some evidence from Sierra Leone suggests that women were the main decision-makers of FGM/C and that educational attainment influences decision-making [34].

Factors associated with FGM/C discontinuation include the level of education, religion, ethnicity, urban residence, age at marriage [35], geographical factors [36] and male involvement [37]. Notably, there is a plethora of evidence that education can be an antidote to FGM/C by enlightening women about the practice's shortcomings [38-41]. Overall, daughters of highly educated mothers are less likely to experience FGM/C, relative to daughters of mothers with little or no education [42]. However, it is worth noting that female education has generally been low in Sierra Leone compared to male education [43, 44]. There is a lack of evidence about the intersection between educational levels and FGM/C in Sierra Leone. A recent study explored the relationship between education and women's intention to circumcise their daughters and reported an inverse relationship between education and FGM/C intention [45].

Since FGM/C is socio-culturally entrenched without any political commitment to abandon it $[23,29,30]$, it is worth researching whether double standards exist regarding the abandonment of FGM/C. In Egypt, for instance, although educated women supported the discontinuation of FGM/C, those who had positive cultural conceptions of FGM/C were less likely to discontinue, regardless of educational attainment [46]. This study appears to be the first research that explores the educational attainment of women and women's viewpoints on whether FGM/C should be continued in Sierra Leone. The study could benefit Sierra Leone's public health position by highlighting the need for anti-FGM/C socio-educational Information, Education, and Communication/ Behaviour Change Communication (IEC/BCC) interventions. It will be challenging to end $\mathrm{FGM} / \mathrm{C}$ without identifying and appreciating women's perceptions of the procedure, and how their education levels impact their views.

\section{Methods}

\section{Study setting}

This study was conducted in Sierra Leone, which shares boundaries with Liberia to the southeast and Guinea to the northeast. Sierra Leone has a tropical climate with a diverse environment, ranging from savanna to rainforests, representing a total area of $71,740 \mathrm{~km}^{2}$. The country's population according to the 2015 population and housing census was 7,092,113 [47]. More than half $(4,187,016)$ of the population live in rural areas, whereas $41 \%(2,905,097)$ live in urban centres. Between 2004 and 2015 , the country recorded an annual population growth rate of $3.2 \%$. The sex ratio stands at 96.8 males per 100 females. The report also shows out of the $6,589,838$ people aged three years and above, $55.4 \%$ have attended school while $44.2 \%$ have never attended school. The percentages of males currently in school (39.1\%) and those who ever attended school $(60 \%)$ are higher than their female counterparts (35.3\% and 50.9\% respectively). The proportion of the population that has never attended school in rural areas is $32.7 \%$ and $11.5 \%$ in urban areas. Freetown is the country's capital and largest city. Agriculture is the dominant economic activity. About 78\% of the population is Muslim and $21 \%$ is Christian. The country is divided into five administrative regions (Eastern, Northern, North West, Southern and Western Area) which are further divided into 14 districts [47].

\section{Data source}

This present study utilised data from the women's recode file of the 2013 Sierra Leone Demographic and Health Survey (SLDHS) [31]. This was the second Demographic and Health Survey (DHS) in Sierra Leone. DHS collates data to monitor the population and public health situation of surveyed countries. The 2013 SLDHS explored information on FGM/C and several maternal and child health indicators such as nutrition, exclusive breastfeeding and fertility. The Measure DHS determined the sample to derive a reliable estimate for important variables 
in the country. This occurred by considering the rural/ urban settings together with the four administrative regions and all 14 districts. The sample was stratified and determined in two main stages to achieve representativeness [31]. The response rate for the survey was $99 \%$. The sampling procedure is extensively documented in the report [31]. The authors were granted access to utilise the survey dataset from the Measure DHS Program's website. The dataset is available to the public via https://dhspr ogram.com/data/available-datasets.cfm.

\section{Study variables}

\section{Dependent variable}

The dependent variable for this study was 'discontinuation of FGM/C', drawn from the survey question: 'Do you think that this practice should be continued, or stopped?' The question had the following responses: 'continued-1', 'discontinued-2', 'depends-3', and 'don't know-4.' All women who participated in the 2013 SLDHS responded to this question regardless of their FGM/C status. Our study included those who answered 'continued' coded as ' 0 ' and 'discontinued' coded as ' 1 '. We excluded those who answered 'depends-3' and 'don't know-4', who comprised $4.6 \%$ and $3.1 \%$ of the total sample respectively. They were excluded to align the data to our study purpose (to investigate the respondents' definite viewpoint on whether FGM/C should be discontinued). Out of the 16,658 women who participated in the SLDHS, 15,228 were included in our study.

\section{Independent variable}

The principal independent variable for the study was 'level of education'. The study followed the original categorisation of the variable by the DHS: no education, primary, secondary and higher. We adopted the level of education' as the principal independent variable because consistent evidence has suggested that education is associated with FGM/C continuation [45, 48-53]. Therefore, we wanted to explore women's position about the discontinuation of FGM/C, based on their educational level. Informed by previous studies on FGM/C [33, 41, 5456], the researchers included some socio-demographic characteristics as covariates. These are age, religion, whether FGM/C is required by religion, wealth, marital status, respondent has daughters at home, residential status, social acceptance of FGM/C circumcision status and region. Religion was recorded as 'Christianity-1, 'Islam-2' and 'Other-3' to make it conceptually relevant and meaningful for analysis. In the DHS, wealth is a composite measure computed by combining data on a household's ownership of carefully identified assets, including a television, bicycle, materials used for house construction, sanitation facilities and type of water access. Principal component analysis was used to transform these variables into a wealth index by placing individual households on a continuous measure of relative wealth. The DHS segregates households into five wealth quintiles: poorest, poorer, middle, richer and richest [57].

\section{Data analysis}

The study employed a descriptive analysis followed by binary logistic regression analysis. The descriptive analysis calculated the women's proportion according to educational level, socio-demographic characteristics and the continuity/discontinuity of FGM/C, as shown in Table 1 . The socio-demographic characteristics are presented as frequencies and percentages, and sample weight was applied at this stage to offset possible weaknesses such as unequal probabilities and non-coverage of some populations [58]. Significant associations were tested between education, each socio-demographic variable and the continuation/discontinuation of FGM/C. Significance was set at a 95\% confidence level. Two binary logistic regression models were developed in a hierarchical manner. The crude model (Model I) only accounted for the level of education and continuation/discontinuation of FGM/C. The adjusted model (Model II), included all socio-demographic variables in addition to education (shown in Table 2).

All the socio-demographic variables were included because they were significantly associated with FGM/C continuation/discontinuation, as illustrated in Table 1 . The survey command (svy) in STATA was applied to account for the survey's complex sampling procedure. Variance inflation factor (VIF) was used to investigate whether multicollinearity existed between the variables. It was found that there was no multicollinearity (maximum VIF=3.8, Minimum VIF=1.2, Mean VIF=1.76). All analyses were conducted in STATA version 13.0.

\section{Ethics approval}

Ethical approval for the 2013 SLDHS was provided by the Ministry of Health and Sanitation of Sierra Leone and the DHS Program's ethics committee. Informed consent was sought from all participants during the fieldwork. The authors applied and were granted access to utilise the data from the Measure DHS Program's website. The dataset is freely available to the public via https://dhsprogram .com/data/available-datasets.cfm.

\section{Results \\ Education, sociodemographic characteristics, and discontinuation of $\mathrm{FGM} / \mathrm{C}$}

More than half of the participants had no formal education (56.5\%). In addition to education, all 
Table 1 Education, socio-demographic characteristics and FGM/C $(n=15,228)$

\begin{tabular}{|c|c|c|c|c|c|}
\hline \multirow[t]{2}{*}{ Variable } & \multirow[t]{2}{*}{ Weighted (n) } & \multirow[t]{2}{*}{ Percentage (\%) } & \multicolumn{2}{|l|}{ FGM } & \multirow[t]{2}{*}{$\mathrm{X}^{2}, \mathrm{p}$-value } \\
\hline & & & Continued (\%) & Discontinued (\%) & \\
\hline \multicolumn{6}{|l|}{ Education } \\
\hline No education & 8597 & 56.5 & 84.4 & 15.6 & $172.3, p<0.001$ \\
\hline Primary & 2116 & 13.9 & 77.0 & 23.0 & \\
\hline Secondary & 4067 & 26.7 & 58.7 & 41.3 & \\
\hline Higher & 448 & 2.9 & 34.5 & 65.5 & \\
\hline Age & & & & & $424.4, p<0.001$ \\
\hline 15-19 & 3426 & 22.5 & 65.0 & 35.0 & \\
\hline $20-24$ & 2446 & 16.1 & 69.4 & 30.6 & \\
\hline $25-29$ & 2603 & 17.1 & 75.0 & 25.0 & \\
\hline $30-34$ & 2123 & 13.9 & 79.7 & 20.3 & \\
\hline $35-39$ & 2097 & 13.8 & 81.1 & 18.9 & \\
\hline $40-44$ & 1275 & 8.4 & 83.5 & 16.5 & \\
\hline $45-49$ & 1258 & 8.2 & 85.8 & 14.2 & \\
\hline Religion & & & & & $858.1, p<0.001$ \\
\hline Islam & 11,997 & 78.8 & 80.3 & 19.7 & \\
\hline Christianity & 3185 & 20.9 & 55.5 & 44.5 & \\
\hline Other & 37 & 0.2 & 82.1 & 17.9 & \\
\hline None & 9 & 0.1 & 100 & 0.0 & \\
\hline FGM required by religion & & & & & $271.6, p<0.001$ \\
\hline Yes & 8917 & 58.6 & 90.6 & 9.4 & \\
\hline No & 5051 & 33.2 & 47.8 & 52.2 & \\
\hline Don't know & 1260 & 8.2 & 69.6 & 30.4 & \\
\hline Wealth & & & & & $875.3, p<0.001$ \\
\hline Poorest & 2875 & 18.9 & 85.1 & 14.9 & \\
\hline Poorer & 2767 & 18.2 & 82.3 & 17.7 & \\
\hline Middle & 2895 & 19.0 & 81.2 & 18.8 & \\
\hline Richer & 3063 & 20.1 & 73.8 & 26.2 & \\
\hline Richest & 3628 & 23.8 & 57.1 & 42.9 & \\
\hline Marital status & & & & & $786.4, p<0.001$ \\
\hline Never in union & 4212 & 27.7 & 59.3 & 40.7 & \\
\hline Currently in union & 10,085 & 66.2 & 81.2 & 18.8 & \\
\hline Formerly in union & 931 & 6.1 & 80.1 & 19.9 & \\
\hline Residential status & & & & & 542.6, $p<0.001$ \\
\hline Urban & 5387 & 35.4 & 64.9 & 35.1 & \\
\hline Rural & 9841 & 64.6 & 81.6 & 18.4 & \\
\hline Daughters at home & & & & & $422.8, p<0.001$ \\
\hline 0 & 7930 & 52.1 & 68.3 & 31.7 & \\
\hline 1 & 4269 & 28.0 & 80.0 & 20.0 & \\
\hline 2 & 2097 & 13.8 & 84.5 & 15.5 & \\
\hline 3 & 735 & 4.8 & 87.0 & 13.0 & \\
\hline 4 & 159 & 1.0 & 89.0 & 11.0 & \\
\hline 5 or more & 38 & 0.3 & 84.2 & 15.8 & \\
\hline Circumcised & & & & & $201.9, p<0.001$ \\
\hline No & 1467 & 9.6 & 39.8 & 60.2 & \\
\hline Yes & 13,761 & 90.4 & 78.6 & 21.4 & \\
\hline Social acceptance of FGM/C & & & & & $301.2, p<0.001$ \\
\hline No & 7018 & 46.1 & 58.0 & 42.0 & \\
\hline Yes & 8210 & 53.9 & 89.1 & 10.9 & \\
\hline Region & & & & & $807.6, p<0.001$ \\
\hline
\end{tabular}


Table 1 (continued)

\begin{tabular}{lllll}
\hline Variable & Weighted $(\mathbf{n})$ & Percentage (\%) & FGM & \multicolumn{1}{c}{$\mathbf{X}^{\mathbf{2}}, \mathbf{p}$-value } \\
\cline { 4 - 5 } & & & Continued (\%) & Discontinued (\%) \\
\hline Eastern & 3388 & 22.3 & 78.4 & 21.6 \\
Northern & 5774 & 37.9 & 79.3 & 20.7 \\
Southern & 3132 & 20.6 & 79.9 & 20.1 \\
Western & 2934 & 19.3 & 52.1 & 47.9 \\
\hline
\end{tabular}

Source: 2013 SLDHS

socio-demographic characteristics had significant associations with FGM/C's discontinuation. Most of the women who had formal education $(65.5 \%)$ and $15.6 \%$ of those without formal education indicated that FGM/C should be discontinued. A significant number of all women surveyed were aged between 15 and 19 years (22.5\%). 35\% of those aged 15-19 indicated that FGM/C should be discontinued. Approximately $79 \%$ of the study participants reported their religion as Islam. About 24\% were categorised as 'richest', and among these, $42.9 \%$ reported that the practice should be discontinued. Also, $66 \%$ of all women in the study were in a union; $18.8 \%$ thought FGM/C should be discontinued compared to $40.7 \%$ of the women who had never been in a union, who thought the practice should be discontinued. Most women in the sample resided in rural locations (64.6\%). Among those not circumcised, six out of ten (60.2\%) stated that FGM/C should be discontinued. More than half of the women (53.9\%) reported that FGM/C is socially accepted, and of these, only $10.9 \%$ thought that the practice should be discontinued (Table 1).

\section{Binary logistic results on education and FGM/C discontinuation}

Results from the binary logistic regression are reported in Table 2. In the unadjusted model (Model I), women with higher education were 13 times more likely to say that FGM/C should be discontinued, compared to those without education [COR 13.24; CI 9.58-18.30]. A similar observation was made when we included women's sociodemographic characteristics, as shown in the adjusted model (Model II). Women with higher education had a higher likelihood of reporting that FGM/C should be discontinued [AOR 4.02; CI 3.00-5.41]. Women aged 45-49 were less likely to report that FGM/C should be discontinued [AOR 0.66; CI 0.48-0.89]. Christian women [AOR 1.72; CI 1.44-2.04], women who said that FGM/C is not required by religion [AOR 8.68; CI 7.29-10.34], wealthier women [AOR 1.37; CI 1.03-1.83] and women from the western part of Sierra Leone [AOR 1.61; CI 1.16-2.23] most commonly stated that FGM/C should be discontinued. However, women in unions [AOR 0.75;
CI 0.62-0.91], circumcised women [AOR 0.41; CI 0.330.52 ] and those from the northern region [AOR 0.63; CI $0.46-0.85]$ were less likely to report that FGM/C should be discontinued (Table 2).

\section{Discussion}

Using a nationally representative sample drawn from the 2013 DHS, this study investigated how educational levels of women of reproductive age in Sierra Leone influence their thoughts about continuity or discontinuity of FGM/C in their country. We found that women with a higher level of education were more likely to support the discontinuation of FGM/C than those without formal education. The impact of formal education efforts to end FGM/C have been significant [49]. A previous study from Sierra Leone also reported that as a woman's educational attainment increases, her intention to subject her daughter to $\mathrm{FGM} / \mathrm{C}$ reduces [45]. These findings potentially indicate that educated women in Sierra Leone do not support FGM/C continuation. This suggests that women's education should be prioritised in Sierra Leone to end FGM/C and thereby enhance the country's chances of achieving SDG target 5.3 [56]. Robertson (2013) explains that educated women are knowledgeable about the health implications of FGM/C and understand the short- and long-term implications of the practice [48]. It is vital to situate FGM/C in the context of intercultural education at basic and secondary levels of education to facilitate efforts to stop the practice, as education alone is not sufficient to end FGM/C [42, 59]. Similarly, Rawat [39], investigating FGM/C across six African countries including Sierra Leone found that education is significant in reducing FGM/C [39]. The current study's findings suggest that education is an important aspect in the fight against FGM/C and educated women may serve as antiFGM/C advocates [50, 60].

Our findings highlight the ways in which wealth supports the discontinuation of FGM/C. Wealthier women and women who live in the western part of Sierra Leone are more likely to support the discontinuation of FGM/C. Concerning the association between wealth and support for the discontinuation of $\mathrm{FGM} / \mathrm{C}$, the findings 
Table 2 Binary logistic results on education and FGM/C discontinuation

\begin{tabular}{lllll}
\hline Variable & \multicolumn{2}{l}{ Model I } & & \multicolumn{2}{l}{ Model II } \\
\cline { 5 - 6 } & COR $95 \% \mathrm{Cl}$ & AOR $95 \% \mathrm{Cl}$
\end{tabular}

Education

No education

Primary

Secondary

Higher

Age

$15-19$

$20-24$

$25-29$

30-34

35-39

40-44

45-49

Religion

Islam

Christianity

Other

None

FGM required by religion

Yes

No

Don't know

Wealth

Poorest

Poorer

Middle

Richer

Richest

Marital status

Never in union

Currently in union

Formerly in union

Residential status

Urban

Rural

Daughters at home

$$
1
$$

2

3

4

5 or more

Circumcised

No

Yes

Social acceptance of

FGM/C

No
Table 2 (continued)

\begin{tabular}{|c|c|c|c|c|}
\hline \multirow[t]{2}{*}{ Variable } & \multicolumn{2}{|c|}{ Model I } & \multicolumn{2}{|c|}{ Model II } \\
\hline & COR & $95 \% \mathrm{Cl}$ & AOR & $95 \% \mathrm{Cl}$ \\
\hline Yes & & & $0.26^{* * *}$ & {$[0.22-0.30]$} \\
\hline \multicolumn{5}{|l|}{ Region } \\
\hline Eastern & & & 1 & {$[1]$} \\
\hline Northern & & & 1.11 & {$[0.85-1.46]$} \\
\hline Southern & & & $0.63^{* *}$ & {$[0.46-0.85]$} \\
\hline Western & & & $1.61^{* *}$ & {$[1.16-2.23]$} \\
\hline
\end{tabular}

Source: 2013 SLDHS

$C O R$ crude odds ratio, $A O R$ adjusted odds ratio

${ }^{*} p<0.05,{ }^{* *} p<0.01,{ }^{* * *} p<0.001$

corroborate previous studies that found a high socioeconomic position helps protect against the practice of FGM/C [46, 61, 62]. Women with a higher level of education are more likely to be wealthy than those with no formal education [63]. Additionally, wealthy females with higher education tend to have less likelihood of FGM/C [56], which is why our finding was anticipated. The observed variation between the rich and poor may imply that women's economic empowerment may reduce FGM/C [64].

Our study also found a geographical pattern regarding support for FGM/C discontinuation. Those residing in the country's western region were more likely to believe that FGM/C should be discontinued, while respondents from the northern region support its continuation. Several studies in Sierra Leone have found the western region residents have a high level of schooling, especially those in Freetown $[65,66]$. Therefore, it is expected that women in the western region were more likely to support FGM/C's discontinuation. With high access to education in the region, women will gain more knowledge about the harmful effects of FGM/C, which may influence their perception of continuation. These findings give the impression that perception about the practice's continuation or discontinuation varies significantly in Sierra Leone and possibly other countries [55]. The observed variations call for further research in the most FGM/C dominant region (northern) to improve understanding of the factors that promote the continuation of FGM/C and allow for appropriate interventions within communities [67].

The WHO stresses that education must be the centrepiece of multi-sectoral efforts aimed at stopping FGM/C [68]. Such measures must involve stakeholders at all levels (local, national and global) and varied sectors (health, economic, justice and education) [68]. These findings must be translated into action, as stating that FGM/C should be discontinued in itself is not sufficient to reduce 
its occurrence. Initial steps could involve strengthening the legal framework and motivating and awarding women who do not cut their daughters. Our study also revealed that despite the positive association between education and support for FGM/C discontinuation, more than half of the women sampled had no formal education. Almost $80 \%$ of them said that FGM/C should continue. This shows that the effectiveness of policies and strategies aimed at eliminating FGM/C will depend on non-formal education, which could target women with no formal education. This can be conducted through community sensitisation of parents, as they are the primary decision-makers regarding $\mathrm{FGM} / \mathrm{C}$ practices.

\section{Strengths and limitations}

One of the significant strengths of this study is that it is the first empirical study on education level and discontinuation of FGM/C in Sierra Leone, to the best of our knowledge. Second, the study is based on a nationally representative sample, a characteristic that makes it possible to generalise with ease. The inclusion of only significant variables reinforces the rigour of the models. The cross-sectional study design should be considered when interpreting the results of the study. Additionally, due to social factors such as religious affiliation and the community's reaction to $\mathrm{FGM} / \mathrm{C}$, social desirability bias is possible.

\section{Conclusion}

Education has been established as an important factor to help prevent the practice among women in Sierra Leone. This implies that FGM/C's discontinuation is a family and social affair, rather than an individual one. Many women will oppose FGM/C if they find themselves in families and communities that support their personal views. Therefore, while attitudinal change is a key step towards ending FGM/C, modification in social norms is required. There is a need to give critical attention to uneducated and poor women, especially those living in the southern part of Sierra Leone who may be at greater risk of FGM/C. Improving their education access is important, as well as linking girls and women to skillsbased employment, particularly those who are already out-of-school, in unions, with daughters at home and those whose societies accept FGM/C. Enhanced access to education and employment may empower them to abandon this harmful practice. Research is also needed to assess whether formal education alone effectively ensures women's support to discontinue FGM/C or if formal education combined with public health education would be more effective.

\section{Abbreviations}

AOR: Adjusted odds ratio; Cl: Confidence interval; COR: Crude odds ratio; DHS: Demographic and Health Survey; FGM/C: Female genital mutilation/cutting; SDG: Sustainable development goals; SLDHS: Sierra Leone Demographic and Health Survey; VIF: Variance inflation factor; WHO: World Health Organisation.

\section{Acknowledgements}

The authors are thankful to the DHS Program for permitting us access to the data used for the study. We also thank Mr. Ebenezer Agbaglo of the Department of English, University of Cape Coast, for copy-editing this document prior to publication.

\section{Authors' contributions}

EKA conceived the study, drafted the conclusion and abstract. BOA, AS and LB conducted the analysis and jointly drafted the methods, results and discussion sections of the manuscript. SY and CN counter checked the study and contributed to compilation of the manuscript. All authors reviewed and approved the final version of the manuscript.

\section{Funding}

No funding was received for this study.

\section{Availability of data and materials}

Data used for the study is freely available to the public via https://dhsprogram .com/data/available-datasets.cfm.

\section{Ethics approval and consent to participate}

Not applicable.

\section{Consent for publication}

Not applicable.

\section{Competing interests}

Sanni Yaya is an Editor in Chief of this Journal.

\section{Author details}

${ }^{1}$ School of Public Health, Faculty of Health, University of Technology Sydney, Sydney, NSW, Australia. ${ }^{2}$ School of International Development and Global Studies, University of Ottawa, Ottawa, Canada. ${ }^{3}$ The George Institute for Global Health, The University of Oxford, Oxford, UK. ${ }^{4}$ Department of Population and Health, College of Humanities and Legal Studies, University of Cape Coast, Cape Coast, Ghana. ${ }^{5}$ College of Public Health, Medical and Veterinary Sciences, James Cook University, Townsville, QLD, Australia.

Received: 8 April 2020 Accepted: 28 October 2020

Published online: 07 November 2020

\section{References}

1. World Health Organisation [WHO]. Female genital mutilation: World Health Organisation; 2018 [cited 2020 February 5]. Available from: https:// www.who.int/news-room/fact-sheets/detail/female-genital-mutilation.

2. UNICEF. Female genital mutilation/cutting: a global concern. New York: UNICEF; 2016.

3. United Nations Children's Fund. Female genital mutilation/cutting: a global concern. New York: UNICEF; 2016.

4. Leye E, Van Eekert N, Shamu S, et al. Debating medicalization of Female Genital Mutilation/Cutting (FGM/C): learning from (policy) experiences across countries. Reprod Health. 2019;16:158.

5. UNFPA, UNICEF, UNHCR, UNIFEM, WHO, FIGO, et al. Global strategy to stop health-care providers from performing female genital mutilation. Geneva: World Health Organisation; 2010.

6. Brady M. Female genital mutilation: complications and risk of HIV transmission. AIDS Patient Care STDs. 1999;13(12):709-16.

7. Olaniran AA. The relationship between female genital mutilation and HIV transmission in sub-Saharan Africa. Afr J Reprod Health. 2013;17(4 Spec No):156-60. 
8. UNAIDS (2008). Uniting against female genital mutilation. https://www. unaids.org/en/resources/presscentre/featurestories/2008/march/20080 304jointstatementfgm. Accessed 22 Sept 2020.

9. lavazzo C, Sardi TA, Gkegkes ID. Female genital mutilation and infections: a systematic review of the clinical evidence. Arch Gynecol Obstet. 2013;287(6):1137-49.

10. Kaplan A, Hechavarría S, Martín M, Bonhoure I. Health consequences of female genital mutilation/cutting in the Gambia, evidence into action. Reprod Health. 2011;8:26. https://doi.org/10.1186/1742-4755-8-26.

11. Berg RC, Underland V. Immediate health consequences of female genital. Norwegian Knowledge Centre for the Health Services (NOKC)(Nasjonalt kunnskapssenter for helsetjenesten) Magne Nylenna, Director; 2014.

12. Bishai $D$, Bonnenfant $Y$, Darwish $M$, et al. Estimating the obstetric costs of female genital mutilation in six African countries. Bull World Health Organ. 2010;88(4):281-8.

13. Chibber R, El-Saleh E, El Harm J. Female circumcision: obstetrical and psychological sequelae continues unabated in the 21 st century. J Mater Fetal Neonatal Med. 2011;24(6):833-6.

14. Sarayloo K, Roudsari RL, Elhadi A. Health consequences of the female genital mutilation: a systematic review. Galen Med J. 2019;8:1336.

15. Elmusharaf S, Elkhidir I, Hoffmann S, Almrotha L. A case-control study on the association between female genital mutilation and sexually transmitted infections in Sudan. BJOG Int J Obstet Gynaecol. 2006;113(4):469-74.

16. Hodal K. Girl, 10, dies after female genital mutilation in Sierra Leone. London: The Guardian; 2018.

17. UN General Assembly. Intensifying global efforts for the elimination of female genital mutilations. UN GA, A/C. 2012;3:67.

18. United Nations. Transforming our world: the 2030 agenda for sustainable development. Geneva: United Nations; 2015.

19. UNFPA, UNICEF. UNFPA-UNICEF Joint Programme on Female Genital Mutilation/Cutting: Accelerating Change. Summary Report of Phase I 2008-2013. United Nations Population Fund; 2014.

20. The Sixty-first World Health Assembly. Female genital mutilation: World Health Assembly; 2008.

21. World Health Organization. Global strategy to stop health-care providers from performing female genital mutilation. Geneva: World Health Organization; 2010. Contract No.: WHO/RHR/10.9.

22. Bjälkander O, Grant DS, Berggren V, Bathija H, Almroth L. Female genital mutilation in Sierra Leone: forms, reliability of reported status, and accuracy of related demographic and health survey questions. Obstet Gynecol Int. 2013. https://doi.org/10.1155/2013/680926.

23. Ibrahim AF. The Bondo Society as a political tool: examining cultural expertise in Sierra Leone from 1961 to 2018. Laws. 2019;8(3):17.

24. Foundation for Women's Health Research and Development (FORWARD). "If you go into the Bondo Society, they will honour and respect you": research on Female Genital Mutilation in Freetown, Sierra Leone. London: Foundation for Women's Health Research and Development; 2017.

25. Koso-Thomas O. Circumcision of women: a strategy for eradication. London: Zed books Ltd.; 1987.

26. Devi S. FGM in Sierra Leone. The Lancet. 2018;391(10119):415.

27. Yoder PS, Wang S, Johansen E. Estimates of female genital mutilation/cutting in 27 African countries and Yemen. Stud Fam Plann. 2013:44(2):189-204

28. Nabaneh S, Muula AS. Female genital mutilation/cutting in Africa: a complex legal and ethical landscape. Int Fed Gynecol Obstet. 2019;145:253-7.

29. Horz J. Dissecting the link between Female Genital Mutilation and politics in Sierra Leone: London School of Economics; 2019 [cited 2020 February 5]. Available from: https://blogs.lse.ac.uk/internationaldevelop ment/2019/05/03/dissecting-the-link-between-female-genital-mutil ation-and-politics-in-sierra-leone/.

30. Behrendt A. Female genital cutting in the Moyamba and Bombali districts of Sierra Leone. Dakar, Sierra Leone: Plan West Africa Regional Office; 2005.

31. Statistics Sierra Leone (SSL) and ICF International. Sierra Leone Demographic and Health Survey. Freetown, Sierra Leone and Rockville, MD: SSL and ICF International; 2013. p. 2014

32. Kandala N-B, Komba PN. Geographic variation of female genital mutilation and legal enforcement in sub-saharan Africa: a case study of Senegal. Am J Trop Med Hyg. 2015;92(4):838-47.
33. Kandala N-B, Shell-Duncan B. Trends in female genital mutilation/cutting in Senegal: what can we learn from successive household surveys in subSaharan African countries? Int J Equity Health. 2019;18(1):25.

34. Bjälkander O, Leigh B, Harman G, Bergström S, Almroth L. Female genital mutilation in Sierra Leone: who are the decision makers? Afr J Reprod Health. 2012;16(4):119-31.

35. Chikhungu LC, Madise NJ. Trends and protective factors of female genital mutilation in Burkina Faso: 1999 to 2010. Int J Equity Health. 2015;14:42.

36. Setegn T, Lakew Y, Deribe K. Geographic variation and factors associated with female genital mutilation among reproductive age women in Ethiopia: a national population based survey. PLOS ONE. 2016;11(1):e0145329.

37. Varol N, Turkmani S, Black K, Hall J, Dawson A. The role of men in abandonment of female genital mutilation: a systematic review. BMC Public Health. 2015;15(1):1034.

38. UNFPA, UNICEF. 17 ways to end FGM/C: Lessons from the field. UNFPA; 2017.

39. Rawat R. The association between economic development, education and FGM in six selected African countries. Afr J Midwifery Women's Health. 2017;11(3):137-46.

40. Waigwa S, Doos L, Bradbury-Jones C, Taylor J. Effectiveness of health education as an intervention designed to prevent female genital mutilation/ cutting (FGM/C): a systematic review. Reprod Health. 2018;15(1):62.

41. Sakeah E, Debpuur C, Oduro AR, Welaga P, Aborigo R, Sakeah JK, et al. Prevalence and factors associated with female genital mutilation among women of reproductive age in the Bawku municipality and Pusiga District of northern Ghana. BMC Women's Health. 2018;18(1):150.

42. UNICEF. Changing a harmful social convention: female genital mutilation/ cutting. Firenze: UNICEF; 2005.

43. Ani KJ, Osakwe C. Girl-child education in post-war Sierra Leone. J Conflictol. $2014 ; 5(2): 5$.

44. Montbleau R (2020). Girls' education in Sierra Leone: a new era in female empowerment. https://borgenproject.org/girls-education-in-sierra-leone 1. Accessed 22 Sept 2020.

45. Ameyaw EK, Tetteh JK, Armah-Ansah EK, Aduo-Adjei K, Sena-Iddrisu A. Female genital mutilation/cutting in Sierra Leone: are educated women intending to circumcise their daughters? BMC Int Health Hum Rights. 2020;20(1):1-1.

46. Dalal K, Lawoko S, Jansson B. Women's attitudes towards discontinuation of female genital mutilation in Egypt. J Injury Violence Res. 2010;2(1):41.

47. Sierra Leone 2015 population and housing census national analytical report. Statistics Sierra Leone. https://sierraleone.unfpa.org/en/publicatio ns/sierra-leone-2015-population-and-housing-census-national-analytical -reporthttps://sierraleone.unfpa.org/en/publications/sierra-leone-2015population-and-housing-census-national-analytical-report. Accessed 23 Sept 2020.

48. Robertson $\mathrm{L}$. Is education the most powerful weapon in the fight against FGM? United Kingdom 2013 [cited 2020 February, 7]. Available from: https://www.28toomany.org/blog/2013/may/14/is-education-themost-powerful-weapon-in-the-fight-against-fgm-blog-by-louise-rober tson-operations-coordinator-at-28-too-many/.

49. Shell-Duncan B. From health to human rights: female genital cutting and the politics of intervention. Am Anthropol. 2008;110(2):225-36.

50. Wodon Q, BankTW, Leye E. Ending female genital mutilation-why education works Global Partnership for Education; 2017 [cited 2020 February, 13]. Available from: https://www.globalpartnership.org/blog/ ending-female-genital-mutilation-why-education-works.

51. Masho SW, Matthews L. Factors determining whether Ethiopian women support continuation of female genital mutilation. Int J Gynecol Obstet. 2009;107(3):232-5.

52. Fikrie Z. Factors associated with perceived continuation of females' genital mutilation among women in Ethiopia. Ethiop J Health Sci. 2010. https ://doi.org/10.4314/ejhs.v20i1.69425.

53. Bogale D, Markos D, Kaso M. Intention toward the continuation of female genital mutilation in Bale Zone, Ethiopia. Int J Women's Health. 2015;7:85.

54. Karumbi J, Gathara D, Muteshi J. "Exploring the association between FGM/C and child marriage: a review of the evidence", evidence to end FGMC Programme Consortium Report. New York: Population Council; 2017.

55. Sipsma HL, Chen PG, Ofori-Atta A, llozumba UO, Karfo K, Bradley EH. Female genital cutting: current practices and beliefs in western Africa. Bull World Health Organ. 2012;90:120-7. 
56. United Nations Children's Fund, Gupta GR. Female genital mutilation/ cutting: a statistical overview and exploration of the dynamics of change. Reprod Health Matters. 2013;21(42):184-90.

57. Inner City Fund (ICF). Demographic and health surveys standard recode manual for DHS7. Rockville, MD: ICF: The Demographic and Health Surveys Program; 2018

58. Bell BA, Onwuegbuzie AJ, Ferron JM, Jiao QG, Hibbard ST, Kromrey JD. Use of design effects and sample weights in complex health survey data: a review of published articles using data from 3 commonly used adolescent health surveys. Am J Public Health. 2012;102(7):1399-405.

59. Azkona EM, Sianes A, Cobo IL. Facing FGM/C through intercultural education: a methodology for secondary school communities. Proc Soc Behav Sci. 2014;132:557-63.

60. GIZ. Female Genital Mutilation and Education: Deutsche Gesellschaft für Internationale Zusammenarbeit (GIZ) GmbH; 2011 [cited 2020 February 7]. Available from: https://www.giz.de/fachexpertise/downloads/giz20 11-en-fgm-bildung.pdf.

61. Abolfotouh SM, Ebrahim AZ, Abolfotouh MA. Awareness and predictors of female genital mutilation/cutting among young health advocates. Int J Women's Health. 2015:7:259.

62. Van Rossem R, Meekers D, Gage AJ. Trends in attitudes towards female genital mutilation among ever-married Egyptian women, evidence from the Demographic and Health Surveys, 1995-2014: paths of change. Int J Equity Health. 2016;15(1):31
63. Miller LC, Joshi N, Lohani M, Rogers B, Mahato S, Ghosh S, Webb P. Women's education level amplifies the effects of a livelihoods-based intervention on household wealth, child diet, and child growth in rural Nepal. Int J Equity Health. 2017;16(1):183.

64. Njue C, Karumbi J, Esho T, Varol N, Dawson A. Preventing female genital mutilation in high income countries: a systematic review of the evidence. Reprod Health. 2019;16(1):113.

65. Wang L. Education in Sierra Leone: present challenges, future opportunities. Washington, DC: World Bank; 2007.

66. Moyi P. An examination of primary school attendance and completion among secondary school Age adolescents in post-conflict Sierra Leone. Res Comp Int Educ. 2013;8(4):524-39.

67. Thomson Reuters Foundation. Country Profile: FGM in Sierra Leone. 28 Too Many; 2018.

68. WHO. Eliminating Female genital mutilation: An interagency statement OHCHR, UNAIDS, UNDP, UNECA, UNESCO, UNFPA, UNHCR, UNICEF, UNIFEM, WHO: United Nations; 2008 [cited 2020 February 7]. Available from: https://www.un.org/womenwatch/daw/csw/csw52/statements _missions/Interagency_Statement_on_Eliminating_FGM.pdf.

\section{Publisher's Note}

Springer Nature remains neutral with regard to jurisdictional claims in published maps and institutional affiliations.
Ready to submit your research? Choose BMC and benefit from:

- fast, convenient online submission

- thorough peer review by experienced researchers in your field

- rapid publication on acceptance

- support for research data, including large and complex data types

- gold Open Access which fosters wider collaboration and increased citations

- maximum visibility for your research: over $100 \mathrm{M}$ website views per year

At BMC, research is always in progress.

Learn more biomedcentral.com/submissions 